\title{
Implementation of lean tools and techniques in an ethical papers production industry
}

\author{
Kukhan S, Bhuvanesh Kumar M $^{*}$
}

Department of Mechanical Engineering, Kongu Engineering College, Perundurai, Erode 638060, India

\begin{tabular}{l} 
ARTICLE INFORMATION \\
\hline Article history: \\
Received: August 5, 2021 \\
Revised: September 16, 2021 \\
Accepted: September 24, 2021
\end{tabular}

Keywords:

Lean manufacturing

Continuous production process

Paper manufacturing industry

$5 \mathrm{~S}$

Kaizen

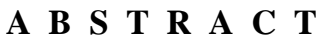

Lean manufacturing (LM) is established as a best practice to improve the performance of manufacturing industries. Not all manufacturing industries realize the benefits of LM practices, specifically continuous process industries. The present research work intends to study the advantages of implementing LM practices in an ethical paper industry, a continuous production industry. Presently, the industry suffers with the problems such as lack of productivity, raw material wastes, underutilized resources, and lack of standard production practices. Gemba technique is adapted to record the information related to the present manufacturing environment. Based on the current state analysis, feasible lean tools such as 5S, Kaizen, and Total Productive Maintenance (TPM) are selected and implemented. The improvements have been noted as reduced tool change over time, reduced material waste, effective resource utilization, and providing safety guidelines to workers and operations. The implications of these improvements increased productivity also.

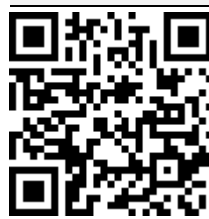

*Corresponding Author

Bhuvanesh Kumar M

E-mail: bhuvanesh.mech@kongu.edu
This is an open-access article under the CC-BY-NC-SA license.

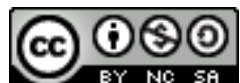

(C) 2021 Some rights reserved

\section{INTRODUCTION}

Manufacturing industries are being affected all over the world by lots of new development, rising advancements in technologies, significant increment in rivalry neighborhood, territorial and worldwide market. Organizations perceive that reliable and restrained utilization of lean techniques on waste elimination and streamlining processes can lead the business to the first-rate of performance [1], [2]. An assortment of progress strategies and approaches are accessible to associations, a significant number of which have yielded empowering implementation success. Lean creation, likewise called lean assembling or lean deduction, as advanced by Womack and Jones [3], is progressively being actualized as a potential answer for some associations, especially within the automotive sectors [4]. Lately, numerous associations both in India and different nations are actualizing the standards and ideas of "lean assembling" with the target of accomplishing a better upper hand over other organizations. Few organizations have achieved their objective, while a considerable lot of them did not.

Lean manufacturing (LM) in India is in the earliest stages and Indian industries are far from making the most of their total advantages [5]. The 
mindfulness level of Indian ventures is extremely low [6]. In India, LM is adapted generally by large manufacturing enterprises (LME). For instance, the TATA MOTORS in India has been such an enterprise by actualizing LM in NANO cars and made an example of overcoming adversity [7]. Indian industries must pick the best possible device as per the work culture, work condition and foundation accessibility of the Indian business [8]. A large portion of the Indians needs the human resources with of endeavors on the planet.

Small manufacturing enterprises (SMEs) are still less competitive due to inefficient processes and less productivity in the Indian context. The primary reason behind this scenario is the lack of up-gradation within their manufacturing system. Specifically, very less continuous processing industries are enjoying the benefits of LM practices. Ethical paper industries suffer with less productivity and different form of wastes. Hence the application of LM practices for ethical paper industries is the need of the hour. The following objectives are framed with reference to the requirements of the present research:

a. To study in detail the wastes generated in a typical continuous production industry considering only the essential core values.

b. To identify the suitable lean tools with the help of literature and experts.

c. To implement the identified lean tools to the case industry.

d. To summarize the improvements attained through LM practices.

\subsection{Problem definition}

The ethical paper industry situated in the southern part of Tamil Nadu, India, has been identified to carry out the study. They produce ethical papers of different standards, thicknesses and volumes as required by the customer. There are existing problems reported by the industry that hampers effective operations. They are found in various forms at various stages of the operations as follows:

a. Production is not meeting the customer requirement, so that the final products are not meeting the consistency in terms of quality.

b. Standardization is in a chaotic form inside the factory. Frequent repair works have been carried out, and reaching the needy tools and equipment is challenging due to a lack of standardization practices. c. Maintenance is quite crucial all over the industry. Presently, the maintenance is not up to the expected level, and it leads to the improper and unnecessary utilization of space and equipment like pumps and tanks.

d. High level of raw material and finished goods inventory cause ineffective service to the customers.

\subsection{Literature review}

Mahapatra and Mohanty [9] have described that the LM is a production management technique based on waste reduction and productivity enhancement through the use of various tools. The authors investigated through a crosssectional sample analysis to find out the reasons for the limited acceptance of LM in Indian manufacturing organizations. The study highlights the knowledge level of Indian managers concerning the philosophy of LM, its adaptability, the inspiring factors leading to its execution, the advantages acquired from it and the application of lean techniques (whether continuous or discrete) to the operating environment. The study finally concludes by highlighting its key areas with a specific implementation model for the application of LM in the continuous process industries.

Panwar, et al. [10] have traditionally investigated the application of LM to discrete manufacturing industries where the parts can easily be assembled and disassembled. While for the process industry, raw materials are blended together to form the final part that cannot be further dismantled. But, the application of LM to process industries is very limited. In addition, there are few systematic reports of lean literature for continuous process industries that may have resulted in a lack of awareness in this sector. It contributes to the categorization of literature in a manner to facilitate the identification of suitable approaches for lean concepts adoption. The literature emphasized the identification of scope and benefits for LM in process industries. The review elaborated the examination of LM applications and their implementation challenges also.

Panwar, et al. [11] identified through literature that "infeasibility to produce in small batches for efficient utilization of capacity" is the primary reason of not implementing lean. "Lack of expertise," "lack of education", and "insufficient training "are further significant causes of low participation of lean implementation 
programs by Indian process industries. Also, 5S, TPM, "work standardization", "quality management", and "visual control" are the LM tools widely adopted by these industries.

\subsubsection{S Tool}

Seiri (sorting) is the first ' $S$ ' in this concept, describing the difference between necessary and unnecessary things. The expression similarly invested for second ' $\mathrm{S}$ ' Seiton (set in order) is "a spot for everything and everything in its place". Seiso (shine) is the third ' $S$ ' that highlights the cleanness and neatness without any sort of dirt and garbage. Dudek-Burlikowska [12] examined that sorting is more helpful in eliminating or getting rid of what is not needed in the workplace, i.e., removing items that are not used in the area, classifying equipment and materials to give redtag to unwanted items. The author also describes that the workplace organization with the higher standard can be guaranteed by the standardization $\left(4^{\text {th }} \mathrm{S}\right)$ maintaining excellent work standards. Every employee's responsibilities and their cleaning duties must be maintained throughout their routine life.

Elango, et al. [13] investigated the setting up of red-tag criteria that one should raise the questions based on, how much is needed? How frequently is it needed? Is it really useful? After this sort of question is answered, the documentation of results must be made up based on improvements. Further, assign fixed places, quantities, and store different items together. People should make $3^{\text {rd }}$ ' $S$ ' as a habit. Higher standard people must ensure their employees work in a clean and effective environment. This $5^{\text {th }}$ ' $S$ ' and is considered to be very challenging to implement. Numerous organizations have done these $5 \mathrm{~S}$ exercises for quite a long time. Yet, it turns out to be exceptionally hard to continue the exercises performed for a more extended time. Advising of the workers ought to be more disciplined normally. Incorporating these steps will gain financial advantages and appropriate improvement [14].

\subsubsection{Kaizen}

Many of the enterprises used to be more beneficial due to this kaizen tool. Kumar and Parameshwaran [15] describe Kaizen as improvising the production process and producing high-quality products with minimal effort. The word "KAIZEN" evolved from two Japanese words "KAI" and "ZEN". "KAI" signifies "Change" and "ZEN" signifies "Better" and "KAIZEN" means "Change for the better". Kaizen is a term used to widely function in the area of quality circles and the manufacturing sector. It associates with a continuous improvement process and generates ideas to make a process better. The idea of Kaizen isn't just constrained to assembling the parts but has augmented its degree to all parts of the business, including the programming and administration industry.

Wickens [16] investigated the roles and responsibilities of every member in the organization, such as manager, boss by taking the example of Nissan Motor Plant in UK. Kaizen's success is mainly depending on the teamwork in the organizations. Successful enactment of kaizen activities in the organization relies on direct communication between every stockholder. Arya and Jain [17] reported that the implementation of Kaizen in the manufacturing of machine vice had shown remarkable impacts on the lead times. Womack and Jones [3] also portraits Kaizen as a tool of "lean philosophy" used to transform the manufacturing world.

\subsubsection{Total productive maintenance (TPM)}

Acharya and Bhatt [18] described that maintenance is crucial to enhancing productiveness and exceptional in production industries. TPM is a method that facilitates productivity growth by reducing waste, proper protection, making the equipment available, and aiming at zero defects, i.e. zero device breakdowns and zero product illness, leading to a boom in productivity by reducing waste. It is a lean technique to optimize the effectiveness of manufacturing devices and tooling. TPM concept has become generic through providing remedies to highly challenging manufacturing issues. TPM aims to maximize the system effectiveness.

Gupta, et al. [19] investigated the issues in confronting unexpected strains and the solutions to diminish assembling cost. The main idea behind the investigation is to provide new and quality items in the market all the time. The India's assembling area is endeavoring hard towards the greatness of operations. Reducing waste and improving the value, higher through put, and progressively proficient frameworks drive India to face an assembling insurgency. 
A decent number of organizations have begun actualizing the scope of business procedures, including going lean and utilizing producing techniques, such as TPM, TQM, Six Sigma, JIT, and so on, to get operational greatness [10]. TPM alludes to an administration framework for advancing the efficiency of assembling gear. An investigation to assess the execution perspectives and achievement elements of TPM activities taken by Indian industries for accomplishing producing greatness is made and reported. There stayed impressive improvements in resolving workers' issues, aptitude level of representatives, innovative up-degree, machine conditions, and consumer loyalty level after TPM. Additionally, the businesses stayed successful in improving their general gear adequacy (OEE) up to $30 \%$, and some of them accomplished the world-class level of 95\% OEE. Adesta, et al. [20] described about the eight pillars of TPM. The pillars include 1) $5 \mathrm{~S}, 2$ ) Autonomous maintenance, 3) planned maintenance, 4) kaizen, 5) quality maintenance, 6) training and education, 7) office TPM, and 8) safety, health and environment.

As a concluding remark, it has been found from the literature review that numerous researchers have investigated the scope for lean assembling in different enterprises. The researches on lean manufacturing in continuous processing industries are very few [21].

\section{RESEARCH METHODS}

The methodology proposed in this study is shown in Fig. 1. The first five steps deals with the identification of the values and problems from the industry. Then, based on the data collected from the industry, suitable lean tools are selected with the help of literature and experts. This is followed by the implementation of selected lean tools to eliminate the identified wastes.

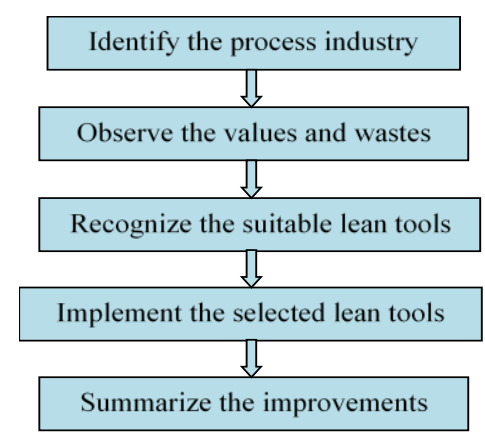

Fig. 1. Methodology

\subsection{Identification of lean tools}

Based on the literature, closer observations during frequent visits, round table meetings with the organization's decision-makers, 5S, Kaizen, and TPM are the major tools to organize the operations effectively.

The 5S stands for five different steps in this approach, as discussed in the literature section. These steps engage to have everything in place, choose what is essential and what is not, keep things in the order, keep the place clean, and set up the appropriate procedure to carry out the operations regularly. In all the way, every step in the $5 \mathrm{~S}$ approach was found to be suitable for the present case industry hence selected for implementation.

TPM is chosen for the industry since TPM emphasizes on the participation of everyone in the organization involved in maintenance activity. There is a lot of places in the industry found to be generating wastes due to poor maintenance. Unless the caution from every employee of the industry on maintenance is ensured, effective resource utilization cannot be achieved by the maintenance team.

The Kaizen helps the organization to enhance its productivity. According to the philosophy of Kaizen, a sequence of small enhancements that are continuously implemented for a long term can result in drastic improvement in a business process. Hence, Kaizen is identified to be suitable to the present case industry.

\section{RESULTS AND DISCUSSION}

The implementation of the selected lean tools such as 5S, Kaizen and TPM are implemented with the help of controlling authorities and decision-makers of the organization and are detailed in subsequent sections.

\subsection{The 5 s concept}

Different locations of the factory were used for storing machinery, utility carts, excess inventory and belongings of workers. The problem ends with the question: how to coordinate the different sections of the organization? The appropriate solution is to incorporate the $5 \mathrm{~S}$ concept.

$5 \mathrm{~S}$ concept aims for continual improvement from the start to end process and ends up in better environment and safety standards. There is a need of developing a common language that can be understood by every stockholder, so people 
can technically communicate with one another within the factory. But, $5 \mathrm{~S}$ practice cannot be implemented without self-discipline. Not only the continuous improvement but many hidden issues can be resolved by $5 \mathrm{~S}$ concept. Organizing $5 \mathrm{~S}$ event will end up in maintaining a higher standard environment within the firm. The quality environment covers both the order and cleanliness. 5S events are Seiri, Seiton, Seiso, Seiketsu and Shitsuke. The results established from the $5 \mathrm{~S}$ events include creating an organized and usable organization, reducing the time period for workers, and reducing supply inventories and adherence to compliance rules.

\subsubsection{Seiri (sorting)}

Seiri emphasizes on sorting through everything in every workplace. It needs keeping only what is essential. Materials, equipment, tools, and supplies that are not often used should be separated and held in a common holding place. Items that have been never used are considered to be surplus and required to be discarded. This facilitates easier reach to the needy items and frees up the additional space. A common approach called "Tagging" which helps in deciding upon the things should be thrown away.

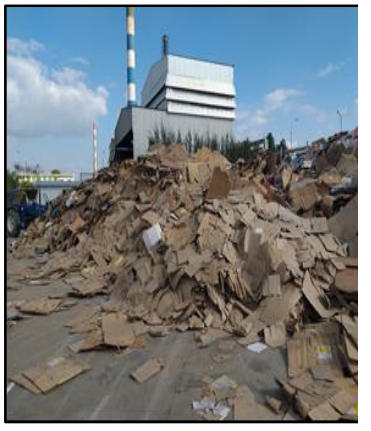

Fig.2. (a)

Unorganized section of raw material

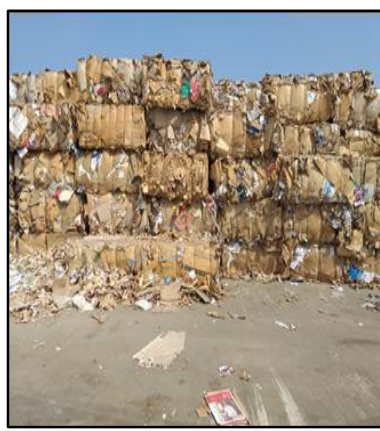

Fig. 2. (b) Organized section of raw material
The tagging can also be used to organize the other items to sort properly. These items are penned with a red tag in which the date and associated information are marked. A place is targeted where the tagged items likely to be discarded. Before implementing the Seiri, the raw materials were not properly maintained and were also not tagged properly as shown in the Fig. 2 (a). This causes the unwanted space utilization over the storing area and creates unsafe situation to the workers who handles it. After implementation, the raw material is properly tagged as shown in Fig. 2 (b) and is properly sorted and maintained. Hence, the unwanted raw material inventory has been reduced and also garbage like setup of raw materials has been improvised to an organized format.

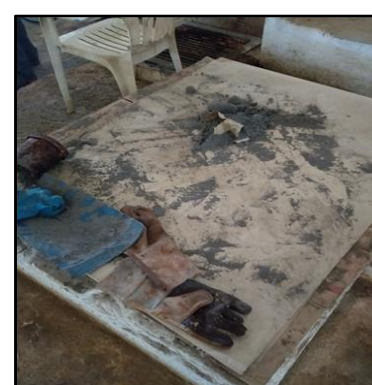

Fig. 3. (a)

Unorganized form of additives

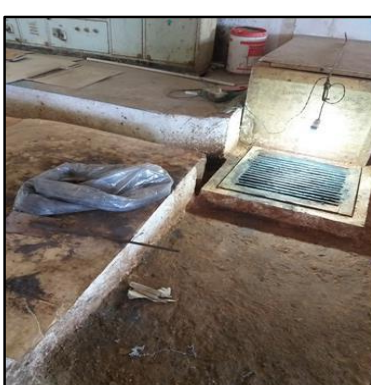
form of additives
Fig. 3. (b) Organized

Fig. 3 (a) and Fig. 3 (b) describes the unorganized and organized form of the over the presence of additives that have been placed in the particular place. The unorganized pattern shows the unwanted wastage due to the open atmosphere. For organizing the additives properly, proper covers and bags have been used to keep the materials.

For the earlier case, to quantify the weight of the materials wasted, they are collected by sweeping them in the surrounding area and weighed using a weighing machine. The quantitative analysis over additives is as follows. Before Sorting:

Totally loaded source by start of shift $\quad=15 \mathrm{~kg}$ Wasted material (muddy color) per shift $=3.5 \mathrm{~kg}$ Reasons: exhaust to atmosphere, improper feeding of source.

After Sorting:

Saved material after sorting in bag $=14.5 \mathrm{~kg}$.

\subsubsection{Seiton (Set in Order)}

Seiton implies Orderliness. It involves setting everything appropriately for simple retrieval. It includes setting all together what is found in Seiri, Straightens and Standardization of it. The procedure emphasizes a simple retrieval of considerable number of items from locations that have been characterized and sorted; markings will usually be adapted to stamp the various storing places. The items much of the time utilized are carried individually, items here and there utilized are put away in a region near the purpose of utilization, and items not utilized at all are independently put away with distinguishing proof. 
The Fig. 4 shows the improper arrangement of the tools in the mechanical store. Due to the improper arrangement leads to additional consumption of time for picking up tools from the store and improper utilization of space. The data has been gathered in the industry for picking a particular part (bearing) from the store as an example.
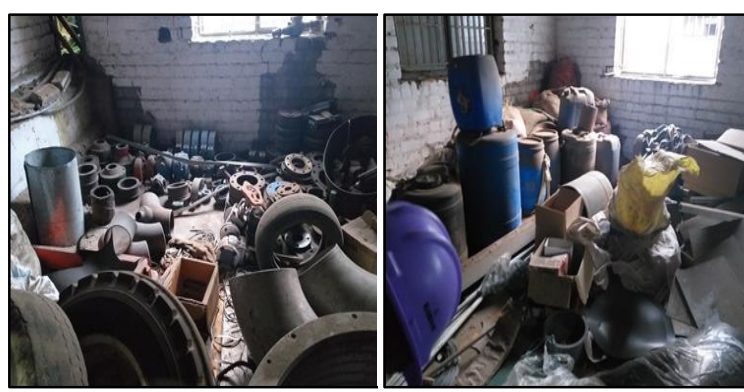

Fig. 4. Before implementation of seiton
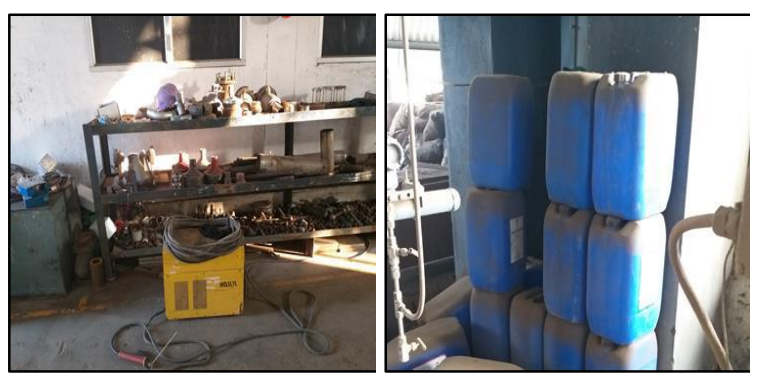

Fig. 5. After implementation of seiton

Fig. 5 shows the proper arrangement of tools in the mechanical store. This appropriate organization reduces the time consumption while picking up tools in the factory's emergency situation. The Seiton implementation also deals with the effective utilization of space by avoiding the empty or waste form of place. Table 1. shows the time for the exchange of tools before and after implementation.

Table 1. Time for exchange of tools before and after implementation

\begin{tabular}{cccc}
\hline S.No & \multicolumn{2}{c}{$\begin{array}{c}\text { Time for } \\
\text { exchange of tools } \\
\text { (seconds) }\end{array}$} & $\begin{array}{c}\text { Improvement } \\
\text { in percentage } \\
\text { form }\end{array}$ \\
& Before & After & \% \\
\hline 1 & 585 & 385 & 65.81 \\
2 & 650 & 385 & 59.23 \\
3 & 565 & 305 & 53.98 \\
4 & 535 & 275 & 51.40 \\
5 & 525 & 275 & 52.38 \\
\hline
\end{tabular}

\subsubsection{Seiso (Shine)}

In the third $S$ event, the focus is given to maintaining cleanliness and a clear work floor area without any form of dirt. In the workplace, the proper form of cleanliness has to be maintained in all shifts of the industry. The Seiso can be done so that the floors and machines must be cleansed at regular intervals. A person must be employed for the checking out of cleaning maintenance, labels and signs can be provided in case of unclean and broken items.

In the Fig. 6, the cleaning is not done properly and not properly inspected by the persons. Due to this, the industry needs to appoint two numbers of workers for the cleaning process. In one complete shift without shield, it requires two times cleaning of that area. It leads to excess appointments and unwanted motions of workers. After implementation, the third S implies over the area and leads the work floor area to shine, as shown in Fig. 7.
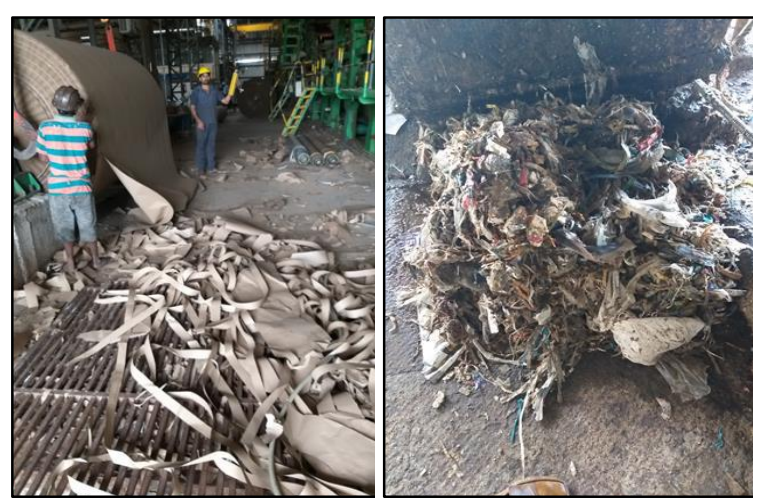

Fig. 6. Before implementation of seiso
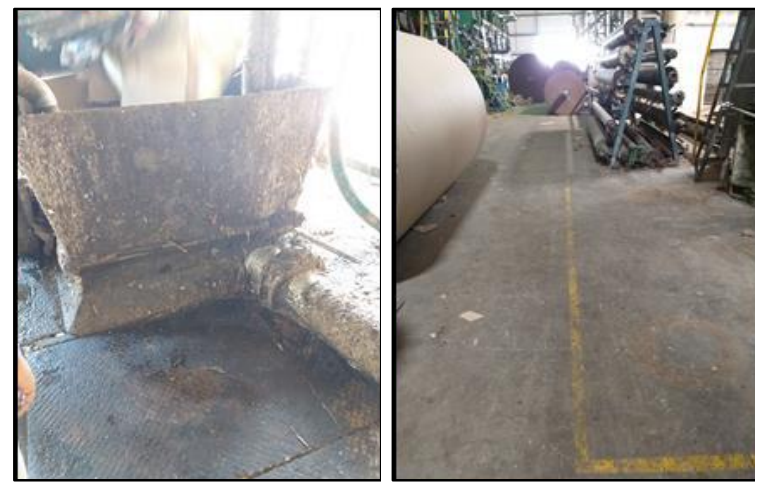

Fig.7. After implementation of Seiso

\subsubsection{Seiketsu (Standardize)}

Seiketsu is the fourth step of the $5 \mathrm{~S}$ event. The step has been derived from Seiso and it enables the work floor area to be in line with the standards of cleanliness. 


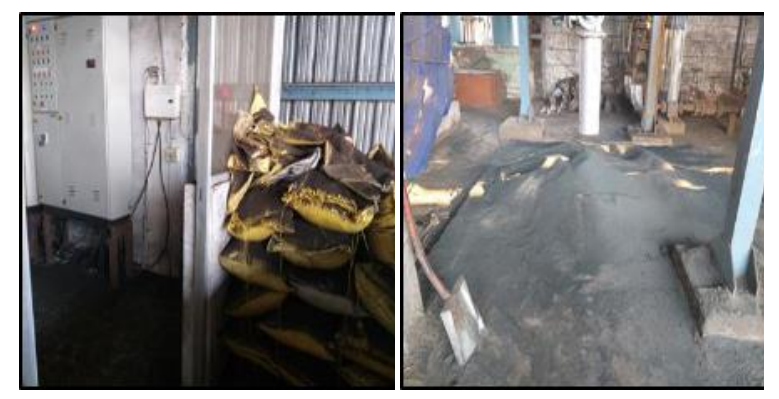

Fig. 8. Before implementation of seiketsu

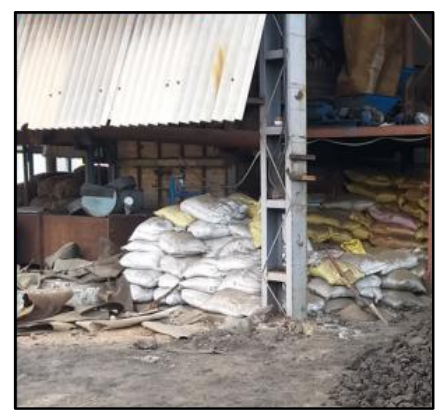

Fig .9. After implementation of seiketsu

The Fig. 8, Fig. 9 \& Fig. 10 shows the standardized form over the industries. Before standardization, the powder bags were improperly maintained near the electric board area, and also the powder form of waste exhausted to the atmosphere might affect a nearby working employee.

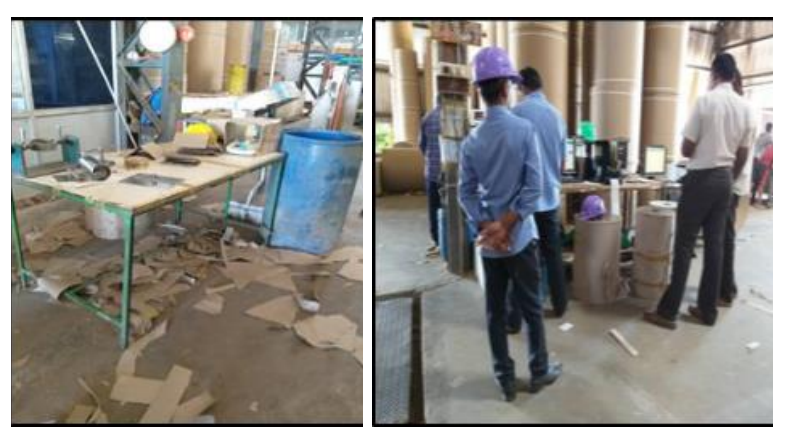

Fig. 10. Before and after implementation of seiketsu

\subsubsection{Shitsuke (Sustain)}

Shitsuke is the fifth step of the $5 \mathrm{~S}$ event. This final step is used to maintain the implementation of the other first $4 \mathrm{~S}$ as a standard methodology to keep the improvement up continuously. The present case study requires routine observations made to the instruments, parts are effectively set, movement barricades are up to date, need of instructions to impart the standards, laborers need to feel their perceived endeavors, and there ought to be grant prize the framework. Fig. 11 \& Fig. 12 shows the overall maintenance of sustaining in the industry by properly maintaining all the four forms of S's in the industry.

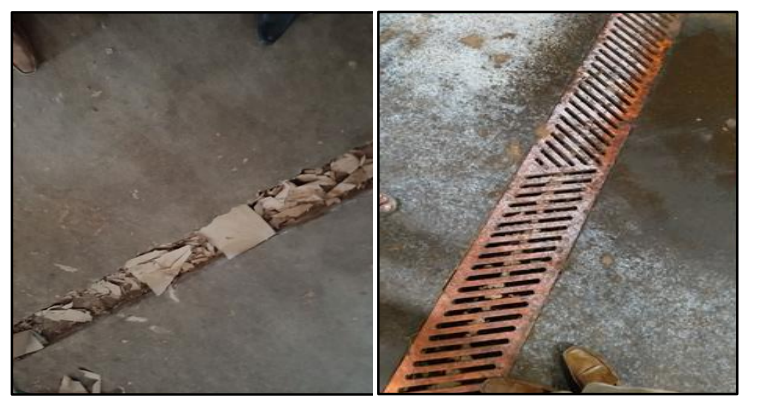

Fig. 11. Before and after implementation of shitsuke

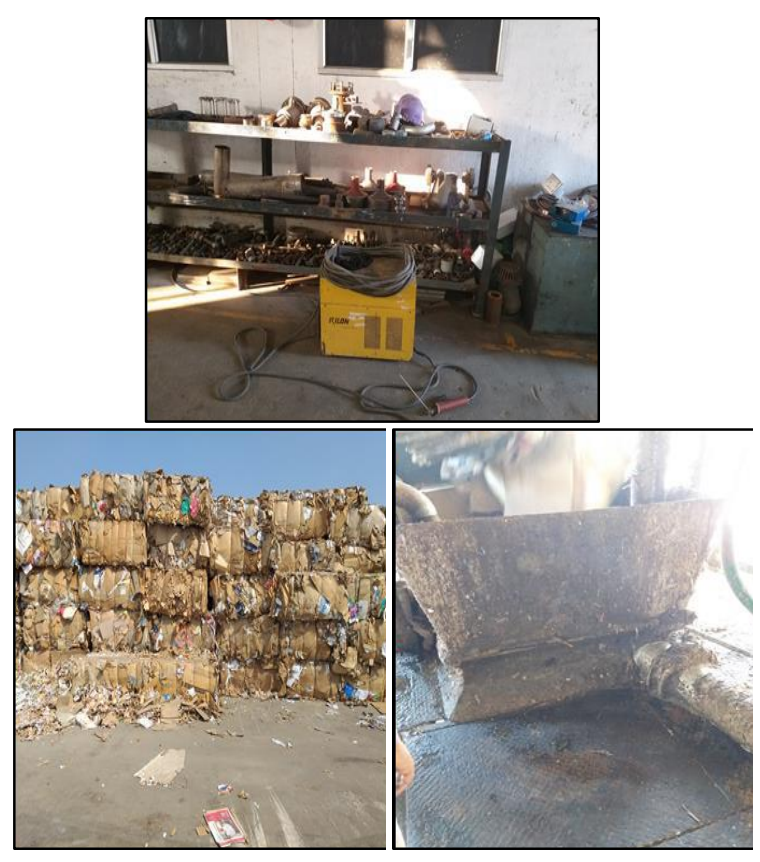

Fig. 12. Overall maintenance of 'sustaining' in the industry

\subsection{Kaizen}

Certain kaizen ideas for the present case study were implemented as follows. The kaizen initiations specific to different problems have been discussed separately in the following sections.

\subsubsection{Kaizen 1}

- Objective: Increase the consistency of the ethical paper and satisfy the customer requirements.

- Problem: The length of the wire part is $33 \mathrm{~m}$ and runs at the speed of $190 \mathrm{~m} / \mathrm{min}$. Due to the short length of the wire part, as shown in the 
Fig. 13 (a), the paper consistency was not done up to the requirements.

- Action and benefits: The action taken is to increase the length of the wire part to $42 \mathrm{~m}$ as shown in the Fig. 13 (b), and speed is to be retained at $190 \mathrm{~m} / \mathrm{min}$. The speed is retained due to the consideration of the paper consistency. The benefits are the satisfaction of the customers and the trust.

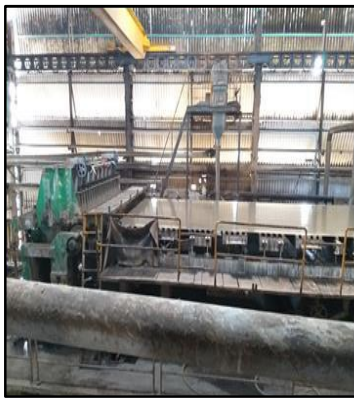

Fig. 13. (a) Before Improvisation

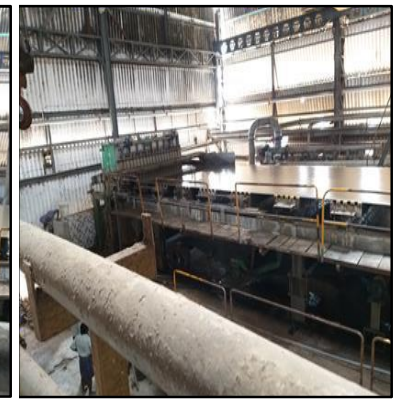

Fig. 13. (b) After Improvisation

\subsubsection{Kaizen 2}

- Objective: The adding up of additional rewinder and with existing re-winder. To deliver final products in right time, reduce the waiting time for trimming and to avoid the inventory, the two setups are necessary.

- Problem: The existing re-winder as shown in the Fig. 14 (a) is used to run at 400rpm and it takes 30min to complete one bundle of paper. Meanwhile, the other finished goods are kept in workspace and consumes the work place.

- Action and benefits: An additional setup of re-winder as shown in the Fig. 14 (b) is made and its speed is increased to 600rpm therefore it completes the bundling process within $15 \mathrm{~min}$. The two setups act together for trimming purpose. It leads to fast completion of trimming, avoids waiting time of products.

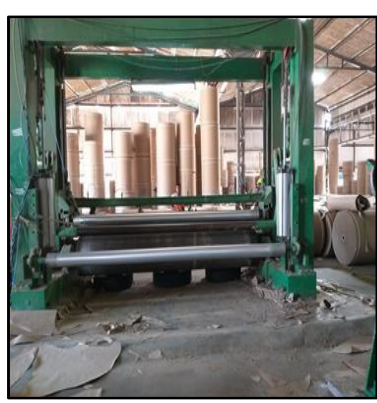

Fig. 14. (a) Before Improvement

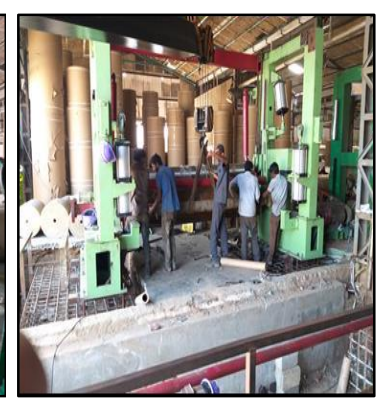

Fig. 14. (b) After Improvement

\subsubsection{Kaizen 3}

- Objective: The addition of a shield to the hopper setup. It is used to avoid the wastage of raw material which is fed inside the hopper.

- Problem: The problem over that area is the wastage of raw material and unsafe conditions to the hopper's employers. In 1 shift without a shield, it leads to two times of cleaning that area. The raw material fed in the conveyor is $45 \mathrm{~kg}$ but due to improper existing design, approx. of $10 \mathrm{~kg}$ raw material gets wasted per shift around the hopper. The waste has been weighed through a weighing machine.

- Action and benefits: The extension need to be provided over the hopper. So, the unsafe condition can be avoided, and the complete fed raw materials would pass inside the hopper without any sort of wastages. Fig.15 (a) shows the hopper setup with unsafe conditions, and Fig. 15 (b) shows the shield to be added over the hopper setup.

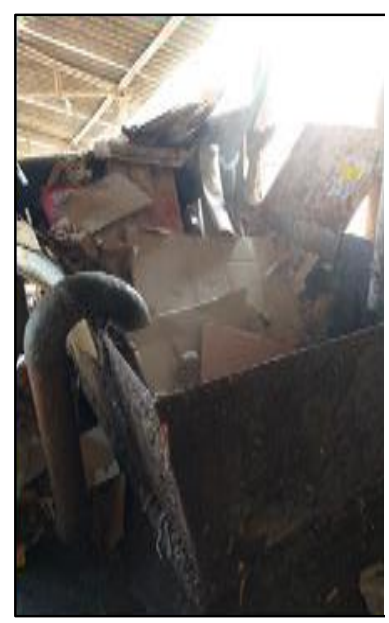

Fig. 15. (a) Existing hopper without shield

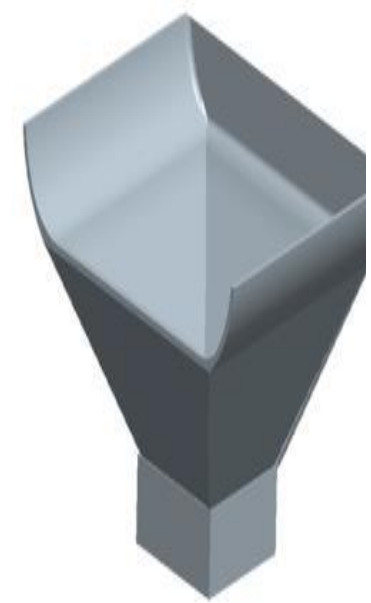

Fig. 15. (b) Shield to be improvised

\subsubsection{Kaizen 4}

- Objective: The Grill setup will be provided over the pulping section.

- Problem: The pulping section is in an unsafe condition for the employees and the pipes placed near the area are isolated.

- Action and benefits: The management suggested to be taken is the provision of grill set up by considering the construction details. Appropriate pipe positioning should be made so that the pulping section would be more safe and clean. Fig. 16 shows the setup without grill section. 


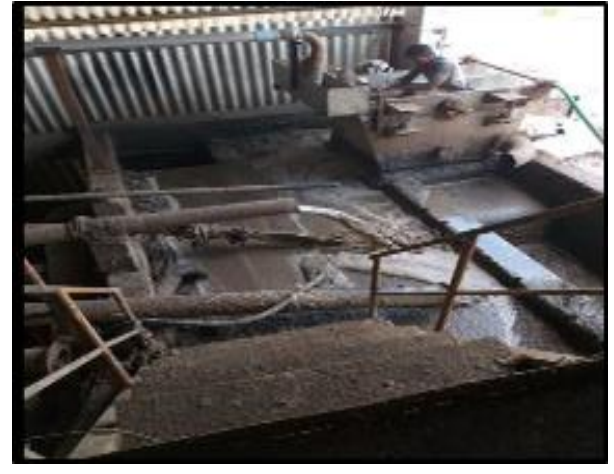

Fig. 16. Setup without Grill Section

\subsection{Total productive maintenance (TPM)}

TPM highlights proactive and preventive maintenance to make the best use of the equipment's operational efficiency. It minimizes the contrast between the roles of production and maintenance by making a strong prominence on empowering workers to help maintain their equipment. The TPM implementation scheme generates a shared responsibility for equipment that motivates the greater involvement of shop floor workers. The TPM ideas have been discussed in the following separate sections for the issues found at different locations.

\subsubsection{TPM 1}

- Objective: The maintenance has to be done on the area of size press. To impart proper maintenance over the press and associated parts that can secure the starch content being wasted unwontedly. Since the starch content is costly, this is an important tool to be incorporated.

- Problem: In the size press, the adding up of starch is done over that equipment. But due to irregular and improper maintenance, the starch is being wasted from the equipment. The quantity of starch waste before TPM implication in the existing feed setup for 100 GSM paper $=2 \mathrm{~kg}$ per every $15 \mathrm{~kg}$ of starch loading.

- Action and benefits: The proper maintenance is followed for the machines and equipment. Also the employees must be trained up to be aware on the respective process. After the TPM, the wastage of resources was totally avoided, leading to cost savings, as shown in Fig. 17.
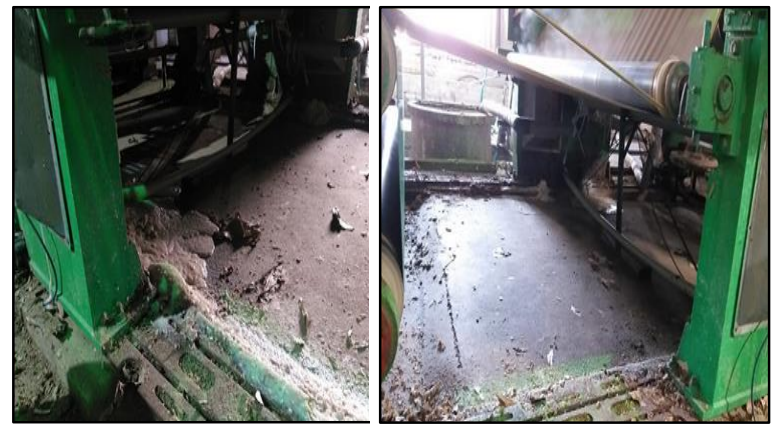

Fig. 17. Before and after TPM1

\subsubsection{TPM 2}

- Objective: The pump must be maintained properly, due to that, the wastage of the liquid pulp from the pump would be avoided.

- Problem: The Improper maintenance of the pump it leads to the wastage of the liquid pulp from the pump. The leakage of liquid pulp from pump is estimated to be 45 liters per shift.

- Action and benefits: After the implementation of TPM, the wastage of liquid pulp has been totally avoided as shown in Fig.18.

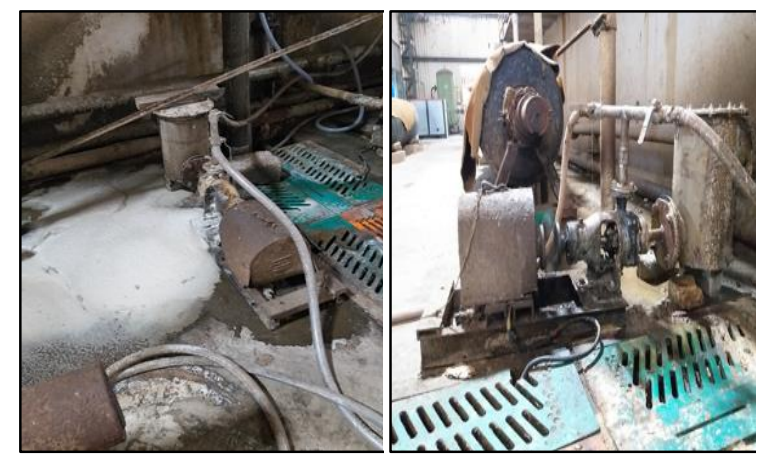

Fig. 18. Before and after TPM2

\subsubsection{TPM 3}

- Objective: The water tank and the pump must be regularly maintained; hence the wastage of the resource of water would be avoided.

- Problem: The Improper maintenance of the pump and the tank leads to the wastage of resources of water, as shown in Fig. 19. The leakage of water from a small storage tank per day is approximated to about 50-60 liters

- Action and benefits: After the implementation of TPM, the wastage of water resources has been totally avoided. 

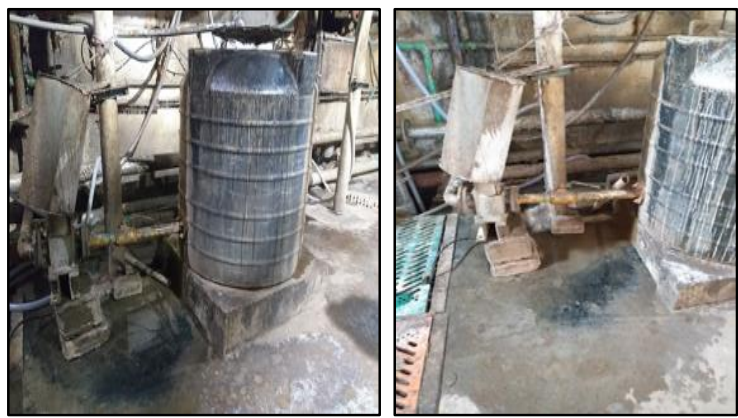

Fig. 19. Before and after TPM3

\section{CONCLUSION}

The review of the research articles revealed that few specific tools such as 5S, Kaizen, and TPM are more frequently used in process industries. But literature pertaining to the Indian process industries that realize the benefits of lean implementation are very few.

The present study investigates the improvements attained by an ethical paper manufacturing process industry through lean manufacturing tools/techniques. The tools are identified from the earlier case study-based research works. Implementations of selected lean tools are done with the help of decision-makers, engineers and supervisors of the organization. The existing and future scenarios of lean implementation are compared for every lean tool. The results portray that the material wastes could be minimized up to zero percentage, considerable change over time, improved utilization of resources, and clean environment motivates the worker to do their job better. The management has agreed that the changes would yield cost savings to the industry. Thus by achieving the positive results, the formed objects of the present study are met. As a concluding remark, it is recognized that the lean tools have a higher impact on improving the process industries' performance.

The major limitation of this study is not including the cost-benefit calculation. This is due to the fact that the management is not interested to disclose the associated cost information. But, the managerial implications resulting from the case study can further be researched for similar process industries. Future studies can include more number of lean tools to check their applicability in process industries.

\section{REFERENCES}

[1] O. O. Mejabi, "Framework for a lean manufacturing planning system," Int. J.
Manuf. Technol. Manag., vol. 5, no. 5-6, pp. 563-578, Jan. 2003, doi: 10.1504/IJMTM.2003.003710.

[2] S. Taj, "Lean manufacturing performance in China: assessment of 65 manufacturing plants," J. Manuf. Technol. Manag., vol. 19, no. 2, pp. 217-234, Feb. 2008, doi: 10.1108/17410380810847927.

[3] J. P. Womack and D. T. Jones, "Beyond Toyota: How to root out waste and pursue perfection.," Harv. Bus. Rev., vol. 74, no. 5, pp. 140-151, 1996. Available: https://hbr.org/1996/09/how-to-root-outwaste-and-pursue-perfection.

[4] V. Swarnakar and S. Vinodh, "Deploying Lean Six Sigma framework in an automotive component manufacturing organization," Int. J. Lean Six Sigma, vol. 7, no. 3, pp. 267-293, Aug. 2016, doi: 10.1108/IJLSS-06-2015-0023.

[5] M. B. Kumar, R. Parameshwaran, J. Antony, and E. Cudney, "Framework for Lean Implementation Through Fuzzy AHP-COPRAS Integrated Approach," IEEE Trans. Eng. Manag., pp. 1-13, 2021, doi: 10.1109/TEM.2021.3089691.

[6] M. Eswaramoorthi, G. R. Kathiresan, P. S. S. Prasad, and P. V Mohanram, "A survey on lean practices in Indian machine tool industries," Int. J. Adv. Manuf. Technol., vol. 52, no. 9, pp. 1091-1101, 2011, doi: 10.1007/s00170-010-2788-y.

[7] J. A. Garza-Reyes, H. S. Parkar, I. Oraifige, H. Soriano-Meier, and D. Harmanto, "An empirical-exploratory study of the status of lean manufacturing in India," Int. J. Bus. Excell., vol. 5, no. 4, pp. 395-412, Jan. 2012, doi: 10.1504/IJBEX.2012.047906.

[8] V. Swarnakar, A. kr Tiwari, and A. R. Singh, "Assessing Benefits of Lean Six Sigma Approach in Manufacturing Industries: An Indian Context," in Operations Management and Systems Engineering, Springer, 2021, pp. 127-144, doi: 10.1007/978-981-15-6017-0_8.

[9] S. S. Mahapatra and S. R. Mohanty, "Lean manufacturing in continuous process industry: an empirical study," J. Sci. Ind. Res. (India)., vol. 66, no. 1, pp. 19-27, 2007. Available: http://nopr.niscair.res.in/handle/12345678 9/1104. 
[10] A. Panwar, R. Jain, A. P. S. Rathore, B. Nepal, and A. C. Lyons, "The impact of lean practices on operational performance - an empirical investigation of Indian process industries," Prod. Plan. Control, vol. 29, no. 2, pp. 158-169, Jan. 2018, doi: 10.1080/09537287.2017.1397788.

[11] A. Panwar, R. Jain, and A. P. S. Rathore, "Lean implementation in Indian process industries - some empirical evidence," $J$. Manuf. Technol. Manag., vol. 26, no. 1, pp. 131-160, Jan. 2015, doi: 10.1108/JMTM05-2013-0049.

[12] M. Dudek-Burlikowska, "Quality research methods as a factor of improvement of preproduction sphere," J. Achiev. Mater. Manuf. Eng., vol. 18, no. 1-2, pp. 435438, $2006 . \quad$ Available: http://jamme.acmsse.h2.pl/papers_amme0 6/1181.pdf.

[13] S. Elango, D. Ajay, B. D. Venkatesh, and S. N. Dinesh, "Implementing 5S Practice in Foundry Shop," Int. J. Res. Eng. Sci. Manag., vol. 3, no. 8, pp. 367-370, 2020. Available:

https://www.journals.resaim.com/ijresm/a rticle/view/201.

[14] M. Bhuvanesh Kumar and R. Parameshwaran, "Fuzzy integrated QFD, FMEA framework for the selection of lean tools in a manufacturing organization," Prod. Plan. Control, vol. 29, no. 5, pp. 403-417, Apr. 2018, doi: 10.1080/09537287.2018.1434253.

[15] M. B. Kumar and R. Parameshwaran, "Fuzzy weighted geometric mean approach-based FMEA to prioritize lean failure modes in manufacturing industries," Int. J. Manuf. Technol. Manag., vol. 33, no. 6, pp. 398-427, Jan. 2019, doi: 10.1504/IJMTM.2019.104550.
[16] P. D. Wickens, "Production management: Japanese and British approaches," IEE Proc. A (Physical Sci. Meas. Instrumentation, Manag. Educ., vol. 137, no. 1, pp. 52-54, Jan. 1990, doi: 10.1049/ip-a-2.1990.0007.

[17] A. Kumar Arya and S. Kumar Jain, "Impacts of Kaizen in a small-scale industry of India: a case study," Int. J. Lean Six Sigma, vol. 5, no. 1, pp. 22-44, Jan. 2014, doi: 10.1108/IJLSS-03-2013-0019.

[18] J. P. Acharya and M. J. Bhatt, "A brief literature review on Total Productive Maintenance," Int. J. Adv. Eng. Res. Dev., vol. 1, no. 5, pp. 1-8, 2014. Available: http://www.ijaerd.com/papers/finished_pa pers/ijaerd 14-0168.pdf.

[19] P. Gupta, S. Vardhan, and M. S. Al Haque, "Study of success factors of TPM implementation in Indian industry towards operational excellence: An overview," in 2015 International Conference on Industrial Engineering and Operations Management (IEOM), 2015, pp. 1-6, doi: 10.1109/IEOM.2015.7093740.

[20] E. Y. T. Adesta, H. A. Prabowo, and D. Agusman, "Evaluating 8 pillars of Total Productive Maintenance (TPM) implementation and their contribution to manufacturing performance," IOP Conf. Ser. Mater. Sci. Eng., vol. 290, p. 12024, 2018, doi: 10.1088/1757899x/290/1/012024.

[21] M. B. Kumar and R. Parameshwaran, "A comprehensive model to prioritize lean tools for manufacturing industries: a fuzzy FMEA, AHP and QFD-based approach," Int. J. Serv. Oper. Manag., vol. 37, no. 2, pp. 170-196, Jan. 2020, doi: 10.1504/IJSOM.2020.110337. 